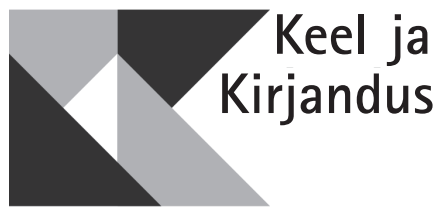

\title{
LAGUNEB? EI LAGUNE?
}

\author{
JOEL SANG
}

$\mathrm{K}$

eele ja Kirjanduse käesolev number võtab vaagida eesti humanitaaria praegust seisu ühe kandi pealt.

Kui vaadata natuke ajas tagasi, siis umbes poole sajandi vältel oli Tartu ülikoolis kindlal positsioonil eriala „eesti filoloogia”, mis koondas enda alla nii keeleteaduse, kirjandusteaduse kui ka folkloristika. Sellel erialal õppijaid kutsuti eesti fillideks. Kuigi eesti fillid pidid kolmandal kursusel spetsialiseeruma, läbisid nad üsna mahuka kursuse igas nimetatud distsipliinis. Kui 1958. aastal asutati ajakiri Keel ja Kirjandus, siis määrati ta profiil lähtuvalt sellestsamast arusaamast, et keel, kirjandus ja rahvaluule kuuluvad olemuslikult kokku. Veel 1970. aastatel paistis strukturalismi võidukäigu valguses asi üsna roosiline, nii et võis rääkida humanitaarteaduste integratsioonist: „... ilmne on, et humanitaarteadused on muutunud ning muutunud nii, et nende sisemised seosed ja ühtekuuluvus on pigem tugevnenud kui nõrgenenud" (Hint 1974: 497).

Praeguseks on pilt kardinaalselt muutunud. Ülikoolis on löödud keeleteadus, kirjandusteadus ja folkloristika otsustavalt lahku. Nüüd kuuluvad nad eraldi seisvate instituutide alla, millel pole üksteisega suuremat pistmist. Ka iga distsipliini sees on toimunud killunemine, üha rohkem tegeldakse klassikalise paradigma suhtes perifeersete teemadega. Tuleb endale aru anda, et teaduse hargnemine on üleüldine pidurdamatu protsess ja on mõnel alal veelgi tormilisem. Näiteks kasvas ajavahemikus 1868-1979 matemaatika eriharude arv 38-lt 3400-le (Davis, Hersh 1982: 29-30). Sellisel taustal kerkib küsimus, kas ei kujuta Keel ja Kirjandus endast anakronismi, püüdes kõnealust vald- 
konda kuidagi koos hoida. Võitluses tsentrifugaaljõududega on toimetus algatanud temaatilised kaksiknumbrid, mis taotlevad kitsamate spetsialiteetide sidustamist ja suuremat üldistusastet.

Et teha mingi revisjon ja otsida oma eksistentsiaalsele küsimusele vastust, kutsus Keel ja Kirjandus 19. veebruaril 2016 kokku konverentsi „Filoloogia lagunemine", mille viimistletud ettekandeid võib lugeda käesolevas numbris. Kahjuks on siit välja jäänud Marju Lepajõe, kel ei olnud mahti oma sõnavõttu artikliks vormistada. See-eest on tagantjärele diskussiooniga liitunud Linnar Priimägi. Püüame järgnevalt esile tuua osalejate põhiseisukohad. Esimese rühma moodustavad laiema haardega mõtteavaldused, kus on vaatluse all filoloogia olemus ja staatus nii minevikus kui ka tänapäeval.

Linnar Priimäe käsitluses („Filoloogia, mida enam pole”) on filoloogiat defineeritud õige avaralt: see on teadus, mis uurib tegelikkuse transformatsiooni tekstiks ja vastupidi. Filoloogia tegeleb kõigega, mille kohta saab midagi öelda, ning on seetõttu universaalne humanitaarteadus. Priimägi vastandab filoloogiat matemaatikale. Matemaatika ei vaja vanu lahendusi, seal on tähtis esimus. Filoloogile on aga klassika ammendamatu varaait ja tõeline filoloog on erudiit. Filoloogia suurkujusid iseloomustavad fundamentaalsed teadmised ja kogemustepagasi kaalukus, mis tagab neile autoriteetsuse ja aristokraatse suveräänsuse. Priimäele on autoriteetideks eelkõige antiikautorid ja Goethe, keda ta korduvalt tsiteerib, aga tunnustust jagub ka Lotmanile.

Kõigest sellest nähtub, et filoloogia parimad päevad on jäänud minevikku: viimati õitses filoloogia semiootika kujul. Tänapäeval on humanitaarteadus muutunud avastusest vormistuseks. Teadustöö väärtust mõõdab nüüd tsitaatide ja viidete arv, kusjuures ei viidata mitte aluslikele autoritele, vaid moemeestele. Filoloogia allakäigu peamine põhjus on humanitaarse üldhariduse hääbumine. (Meil sai see vist alguse nõukogude võimu tulekuga ja on jätkunud pärast taasiseseisvumist uue hooga.) Siiski peavad vähesed alles jäänud filoloogid kõige kiuste täitma oma missiooni: kandma faustlikku vaimu ja hoidma Euroopa ühismälu.

Oma sõnavõtus „Refiloloogia ja selle kolm komponenti” tõdeb Martin Ehala filoloogia killustumist ja leiab, et kunagisel kujul ei õnnestu selle ühtsust enam taastada. Laialdane kompetents ja eruditsioon, mis iseloomustas möödunud aegade filolooge, on tänapäeval haruldane. Seetõttu on tänastel spetsialiseerunud humanitaarteadlastel üha vähem öelda midagi, mis läheks ühiskonnale korda.

Filoloogia määratlemisel lähtub Ehala Nietzschest, kes peab normatiivsust distsipliini oluliseks tunnusjooneks: filoloogia on rahvuse juurte, rahvuskeele ja rahvuskirjanduse uurimine pedagoogilise eesmärgiga kujundada rahvuslikku identiteeti. Tänapäeval on rahvusliku identiteedi asemel esikohal ühiskondlik identiteet ja selle kinnitamiseks läheb vaja uut paketti - refiloloogiat. Millised võiksid olla refiloloogia osised? Esiteks peaksid sinna kuuluma kõik valdkonnad, mis tegelevad keelekasutuse uurimisega funktsionaalsest ja kommunikatiivsest küljest - tekstilingvistika, retoorika, diskursuseanalüüs. Refiloloogia teine komponent on humanitaarteadused - refiloloog ei saa olla kitsalt spetsialiseerunud teadlane. Kolmas komponent on eetika. Kokku moodustab see paketi, millele on ühiskondlik tellimus, identiteediloome kõrval saab seda rakendada ka emakeeleõpetajate koolitamisel. Veel on lingvistilistest distsipliinidest väljavaateid keeletehnoloogilistel suundadel, 
aga grammatikauurimise valdkonnad, mis domineerisid XX sajandil, peavad Ehala meelest taanduma.

Tiit Hennoste „Filoloogia vabastamine Exceli käest. Kubofuturistliku uusfiloloogia programm" annab linnulennulise ülevaate lingvistika ja kirjandusteaduse arengust XIX sajandist tänapäevani. Sünopsis on usaldusväärne ja seda siin ümber jutustada pole mõtet. Hennoste kriitiline toon on üldiselt õigustatud, eriti looja läinud postmodernismi puhul, mille kütkes on veel mitmedki Eesti kirjandusteadlased. Kergelt ülepakutud on ehk väide, et korpusest lähtumine ja kvantitatiivne analüüs on saanud keeleteaduses normiks. Vaadates Keelele ja Kirjandusele laekuvaid artikleid, seda küll ei tähelda.

Hennoste vastandab kvantitatiivset ja kvalitatiivset analüüsi. Kuid kas ei lähe veelahe keeleteaduses mitte mööda keele ja kõne (pr langue/parole) piiri, nii et ühele poole jäävad introspektiivsed-intuitiivsed vaatlused ning teisele poole empiirilised uuringud? Esimest suunda esindab viimasel ajal kognitiivne lingvistika, mis meilgi jõudsalt juuri ajab. Perspektiivika uurimismeetodina tõstab Hennoste esile vestlusanalüüsi, mis tõotab olla läbinisti analüütiline: „Ühtlasi on väga oluline mitte „ronida” kõnelejale pähe....” Vestlusanalüüs on Hennoste sõnul ka tõhus vahend kirjandusteoste analüüsimiseks. Näidendite puhul see ilmselt kehtib, aga kuidas on lugu monoloogilise proosaga? Siingi on Hennoste meelest tegemist dialoogiga, kujuteldava dialoogiga autori ja lugeja vahel. Aga selleks, et tabada lugeja imaginaarset kõnevooru, tuleb ikkagi ronida tema pähe. ${ }^{1}$

Mati Hint („Mõõtmised ei loo teooriat”) annab ülevaate filoloogia põhikomponendi, keeleteaduse arengust XX sajandil, keskendudes foneetikale ja fonoloogiale. Kuigi viimased on saja aasta jooksul täielikult teisenenud, pole filoloogia arhitektuur kuigivõrd muutunud. Üha rohkem rakendatakse küll kvantitatiivseid meetodeid, mõõtmist ja statistikat, kuid keeleteaduse tuuma moodustavad ikkagi loogilisel deduktsioonil põhinevad teooriad. Keele ja kõne olemuse kontseptsioone ei töötata välja mõõtmistulemuste põhjal, vaid need on intuitiivse mõttetöö viljad. Traditsiooniline filoloogia oli avastav teadus. Kuid nüüd on avastamise ja leiutamise piir hägustumas, sest lisandunud on keeleteaduse tehnoloogilised rakendused (kõnesüntees, kõnetuvastus, keelestatistika jt).

Peale kõne- ja keeletehnoloogia lahkulöömise keeleteadusest on veel teisigi filoloogia fragmenteerumise märke, kas või ilukirjanduse ja sõnaliste tekstide tähtsuse vähenemine. Samas on eesti filoloogia kui rahvuskultuuri ülioluline komponent osa Eesti riigi olemasolu õigustusest. Ja eesti filoloogia käekäik on otseselt seotud Eesti ülikooliga. Traditsiooniliselt tähendas eesti filoloogia keelepool eesti keele kõigi struktuuritasandite tundmist. Filoloogi haridus pidi andma nii tänapäeva eesti kirjakeele, õigekeelsuse ja terminiõpetuse kui ka murrete tundmise. Praegu on aga Tallinna Ülikooli õppekava üsna juhuslik, koostatud käepärast olevate õppejõudude harrastustest lähtudes.

Mati Hindi kriitikale vastab rubriigis „Väiteid ja vastuväiteid” Tallinna Ülikooli eesti kirjanduse professor Piret Viires, kuulutades: „Eesti filoloogia on elus!"

\footnotetext{
${ }^{1}$ Vrd sedastusega kognitiivse lingvistika alalt: „Suhtlusvaldkonnas tuleb välja töötada analoogiline edastatavate infoüksuste ning suhtlusruumi parameetrite ja mõjufaktorite tüpoloogia, samuti nendevaheline korrelatsioon, ehk konkreetselt: käsitus sellest, mis toimub suhtleja „peas”...” (Õim, Koit 2014: 188).
} 
Artiklis „Koost lagunev või uuenev folkloristika? Filoloogilisi vaateid” visandab Ülo Valk folkloristika sünniloo ja eritleb ideoloogilisi hoovusi, mis seda suunasid.

Distsipliini kutsus ellu romantismile omane arusaam, et aja jooksul on kaduma läinud inimkonna algne vaimne ühtsus, millest on veel jälgi rahvaluules ja mida õnnestub ehk taastada. Balti provintsides sai folkloristika konkreetsema ülesande: äratada rahvuslik eneseteadvus. Selleks toetuti rahvalaulule ja üritati konstrueerida maarahvale Skandinaavia mõõtu mütoloogiat. Peagi leiti rahvuslusele ka laiem taustsüsteem - soome-ugri ja uurali ühtsus, kust otsida oma juuri.

Folkloristikale on olnud algusest peale omane teatav nostalgiline häälestatus, kinnismõte, et rahvaluule kuldaeg on kauges minevikus. Pärimuskultuuri hääbumise kõrval on nähtud vaimusilmas ka folkloristika väljasuremist. See kartus on alusetu, leiab Valk, viimase aja arengud annavad tunnistust folkloristika institutsionaalse kandepinna tugevnemisest. Tõsi, mõne aja eest seadis postmodernistlik lammutamistuhin kahtluse alla isegi folkloori mõiste, aga tänaseks on kontseptuaalsest hämarolekust välja tuldud. Muutunud on empiirika ja taandumas on pikka aega valitsenud arusaam, et rahvaluulet peab mõistma tekstikogumi või žanrisülemina, mida põlvest põlve edasi pärandatakse. Folkloor pole niivõrd sõnaline materjal, mida kultuuris edasi antakse, kuivõrd tegevus, mille käigus midagi valmib või juba tuttav saab uue ilme. Selle tõdemusega kaugeneb folkloristika filoloogiast, mille keskmes on tekst. Samas pole sidemed päriselt katkenud, sest folkloristikal on ühishuvisid teiste filoloogia alla kuuluvate distsipliinidega, näiteks kognitiivse ja korpuslingvistikaga.

Kristiina Ross („Eesti filoloogia sünd ja kirikulaulude tõlked”) vaatleb eesti filoloogia eellugu, vaimuliku kirjavara teedrajavat rolli suutliku kirjakeele kujundamisel.

Kirjalik eesti keel hakkas kujunema XVI sajandi pastorite tõlketegevuse tulemusel. Esialgu tõlgiti kirikulaule nagu proosateksti, tõlked olid kohmakad ja sisult segased sõnasõnalised ümberpanekud. Esimesed säilinud kirikulaulude värsstõlked ilmusid 1656. aasta lauluraamatus. Need on vormilise ja kujundliku külje poolest suur samm edasi, kuid jäid eestikeelsele kogudusele arvatavasti üsna kaugeks. XVII sajandi lõpul tõlkisid noored reformaatorid, põhjaeesti kirjakeele loojad Adrian Virginius ja Johann Hornung nii Vana kui ka Uue Testamendi senisest palju ladusamasse keelde ja hakkasid ka laulutõlkeid eestikeelse kogukonna vajadustele kohandama. Revideeritud tõlgete jõudmist üldisesse kasutusse takistas aga algav Põhjasõda. 1721. aastal andsid pietistid välja lauluraamatu, mis terve eesti kogukonna keeleteadvuses midagi oluliselt muutis ja oli kasutusel ligi poolteist sajandit. Ennekõike oli seal taotluseks lihtsus ja lähenemine rahvakeelele. Samas toodi eesti keelde hulgaliselt saksalaenulisi literatuurseid metafoore, mille ärkamisaegne eesti luule hiljem üle võttis. Isegi Lydia Koidula isamaalisele ülemlaulule „Mu isamaa on minu arm” võib leida lauluraamatust vaimuliku paarilise. „Aga kui XIX sajandi ärkamisaegsete eesti lu ule taja te kohta ongi esialgu raske öelda, kas nad laenasid oma kujundid kaasaegsest saksa luulest või olid suure osa neist omaks võtnud juba eestikeelsetest kirikulauludest, siis eesti ärkamisaegse luule lugeja jaoks tulevad pinnase ettevalmistajana kõne alla ainult needsamad pietistlikud kirikulaulud." Igatahes oli eesti kirjakeel jõudnud tänu saksa pastorite tõlketegevusele XIX sajandiks arengujärku, mis 
tegi võimalikuks rahvusromantilise ilukirjanduse sünni ja selle üle arutleva kirjanduskriitika. See tähendas ühtlasi omakeelse eesti filoloogia sündi, tõdeb Ross.

Kui enamik siiani refereeritud autoritest on täheldanud filoloogia fragmenteerumist, siis järgnevad Arne Merilai, Märt Väljataga ning Eva ja Mart Velskri case study'd peaksid olema filoloogia kestva ühtsuse kinnituseks, näidates, kuidas on võimalik kasutada lingvistika arsenali kirjandusteose analüüsimisel.

Arne Merilai „Deiktiline lähilugemine” rakendab kirjandusteose analüüsimisel üht keeleteaduse mõistet, seda oluliselt laiendades. Keeleteaduses nimetatakse deiksiseks kõneldu seostamist kõnelemise füüsilise ümbrusega, st viitesuhete võrgustikku, mis seob omavahel diskursuse maailma ja füüsilise kõneolukorra (vt Pajusalu 2009: 184). Deiktiline väljend paigutub mingisse punkti kolme telje suhtes, millel on ühine nullpunkt ehk origo. Origo on määratud kõneleja ja tema asukohaga ruumis ja ajas. Rollisuhetega seotud deiktikuid nimetatakse isikudeiktikuteks ja nende tüüpilised esindajad on isikulised asesõnad (mina, sina, meie, teie, nemad). Lisaks avaldub isikudeiksis ka tegusõna isikukategoorias. Ruumilisi suhteid väljendavad ruumideiktikud (siin, seal, see, too jne), ajalisi ajadeiktikud (nüüd, praegu, täna, eile, homme jne). Deiktikud on eelkõige pronoomenid ja adverbid, mille tähenduskirjes sisaldub kõneleja kategooria.

Merilai lennukas käsitluses on aga deiksis - üks tema ammustest lemmikteemadest - kõikehõlmav nähtus, peaaegu kogu keelt ja maailma haarav viitestik. Deiktiliseks nullpunktiks ehk origo'ks peab ta lausungit, mitte kõnelejat. Tavapärastele avaldusvormidele lisaks arvab Merilai deiksise alla ka emotsionaalse modaalsuse ehk tundedeiksise, teksti vormiliste üksuste viitamise ette- või tahapoole, sh alg- ja lõppriimi, ehk diskursideiksise, eituse ja antonüümia ehk kontrastideiksise, loodusdeiksise. Merilai läheb veelgi kaugemale, nähes igas sõnas viidet: sõna puu on aktiivselt deiktiline, sest ta viitab horisontaalsele mõõtmele, vihm omakorda implitseerib langemist ülalt alla. Siin astub Merilai juba kognitiivse lingvistika mängumaale, kus üritatakse kirjeldada kõneleja ja kuulaja maailmateadmust. On selge, et paljude sõnade tähenduskirjes on komponendid SUUND ja LIIKUMINE/PAIGALSEIS. Hea tahtmise korral võib ju seda ka deiksiseks nimetada, seda enam, et on võimalik viidata mitmele analüütilise filosoofia või semantika korüfeele. Kuid nagu ikka vaesub mõiste laienemisel tema sisu.

Märt Väljataga „Ajast ja arust ehk tempusest ja teadvusest eesti komplementlauses" tegeleb samuti deiksisega, täpsemalt deiktilise siirdega. Paljudes keeltes teisendab pealause aja nihutamine minevikku ka kõrvallause aja (seda kutsutakse consecutio temporum'iks), mis avaldub komplementlausetes ja eriti selgelt kaudkõnes. Eesti keeles kehtib vastupidine reegel: kõrvallause jääb üldiselt olevikku. Kuid reeglil on ka erandeid ja Väljataga vaatlebki, millest need on tingitud. Kui kõrvallausetes kasutatakse olevikku, siis on tegemist relatiivse tempusega, orienteerumisega mingile kontekstilisele ajahetkele, kui minevikku, siis absoluutse tempusega, keskendumisega lausumishetkele. Kuid ajavalikut mõjutavad muudki tegurid. Väljataga on üles korjanud Wiedemanni tähelepaneku, et kui kõrvallauses kasutatakse preesensit, siis „öeldu paikneb kõneleja ettekujutuses; kui aga öeldut väljendatakse faktina, siis kasutatakse ka eesti keeles preteeriumi", ning jõuab seda Adrian Barentseni toel edasi arendades järeldusele, et kõrvallause aeg sõltub ka pealause 
verbi faktiivsusest. Kui pealause öeldiseks on verbid juhtuma, esinema, ette tulema, sündima, olema minevikus, siis on relatiivne tempus (olevik) kõrvallauses välistatud.

Käsitledes lausungi deiksist, vaatleb Väljataga, kuidas pea- ja kõrvallause on ajaliselt orienteeritud. Pealause deiktiliseks nullpunktiks ehk keskseks orientatsioonipunktiks on selle ütlemishetk. Kõrvallause orientatsioonipunkt, sekundaarne orientatsioonipunkt, on määratud pealause sündmuse või tegevusega. Sellest, kumb neist domineerib, sõltub, kas komplementlauses kasutatakse absoluutset või relatiivset tempust, kas minevikku või olevikku.

Eva ja Mart Velskri artikkel „Lõunaeesti keele tagasitulek proosasse" keskendub ülemöödunud sajandivahetuse jutukirjandusele ja teeb sealjuures mitmeid dialektoloogilisi ja sotsiolingvistilisi tähelepanekuid. Kuigi XIX sajandi lõpul ja XX sajandi alguses taandus lõunaeesti kirjakeel trükisõnast, kinnitas see samal ajal kanda mitme autori proosateostes. Nii rikastas August Kitzberg oma tegelaskõnet Mulgi, Jaan Lattik Võru ja Ernst Enno Tartu murdega, Hermann Julius Schmalz oli aga läbinisti setukeelne. Sel ajal ilmunud tekstid panid aluse murrete kasutamise printsiipidele hilisemas eesti kirjanduses: murret kasutatakse valdavalt otsekõnes, vahel ka tsitaadina kirjakeelses tekstis; murre annab märku sotsiaalsest staatusest, haridusest ja päritolust; murre seostub mälestusliku häälestusega. Üsna levinud on ka murde kasutamine koomilise efekti saavutamiseks.

Kui Priimäe käsitlus avab filoloogia diakroonilised tagamaad, siis Marek Tamme „Tagasipöördumine filoloogia juurde: vaade Ameerikast” pakub siinsele diskussioonile sünkroonilist tausta.

XX sajandil oli filoloogia jäänud ingliskeelses maailmas unarusse, ent 1980. aastatel sai ta seal äkitselt jälle aktuaalseks, kui Paul de Man avaldas artikli „Tagasipöördumine filoloogia juurde”. De Man käsitleb filoloogiat kui tekstide lähilugemise meetodit, mis ei hooli kontekstist ja keskendub dekonstruktivismi vaimus tekstide sisemisele ülesehitusele. Filoloogia taassünni motiiviga haakusid mitmed õpetlased, teiste hulgas „uusfiloloogid”, kes vastupidiselt de Manile rõhutasid vajadust uurida vanu käsikirju kui terviklikke kultuurinähtusi, pöörates tähelepanu nende materiaalsele iseloomule ja sotsiaalsele toimele. Diskussiooniga filoloogia olemuse ja tuleviku üle on liitunud üha uusi sõnavõtjaid, nii et arutelu kestab tänini. Seejuures mõistab igaüks filoloogiat isemoodi. Välja on pakutud mitmeid filoloogia kaasajastamise programme: „maailmafiloloogia”, „postfiloloogia”, „disjunktiivne filoloogia”, „radikaalne filoloogia”, „digifiloloogia” jne.

Mida läbiviidud revisjonist järeldada? Kõigele vaatamata püsib filoloogia korpus veel koos. Keeleteadusest välja kasvanud semiootika on andnud viljakaid siirdeid kirjandusteadusse ja folkloristikasse. Ka sotsiolingvistikal ja kognitiivsel keeleteadusel on naaberdistsipliinidele mõndagi pakkuda. Ent tõsiasi on ka süvenev killustumine ja spetsialiseerumine, mis tähendab seda, et kasvab ahta fookusega publikatsioonide arv, mis on küll laitmatult vormistatud, kuid lähevad korda vaid paarile-kolmele kolleegile. Tunnetusliku väärtusega uurimuste asemele astuvad rakenduslikud näputööd. Öeldu puudutab eeskätt keeleteadust. Kirjandusteaduses ja folkloristikas näib raskuspunkt nihkuvat piirialadele, kus esimene läheb üle kultuuriuuringuteks ja teine etnoloogiaks. Kas neid arenguid tervitada või tõdeda resigneerunult: Sic transit gloria mundi, see sõltub juba hindaja meelelaadist. 


\section{Kirjandus}

Davis, Philip J., Hersh, Reuben 1982. The Mathematical Experience. Boston: Houghton Mifflin Company.

Hint, Mati 1974. Humanitaarteaduste ühtsus - keeleteaduse poolt vaadatuna. Looming, nr 3, lk 487-505.

Paju salu, Renate 2009. Sõna ja tähendus. Tallinn: Eesti Keele Sihtasutus.

Õ i m, Haldur, Ko it, Mare 2014. Keele mõistmise modelleerimine arvutil. Semantika, ontoloogia ja sündmuste esitus kahe valdkonna näitel. - Keel ja Kirjandus, nr 3, lk 169-194. 